\title{
Hereditary gingival fibromatosis: Report of four generation pedigree
}

\author{
Shivlal L Vishnoi
}

\begin{abstract}
Introduction: Gingival enlargement is defined as an overgrowth or increase in size of gingivae. Gingival enlargement is associated with multiple factors including inflammation, medications, neoplasia, hormonal disturbances and rarely heredity. Hereditary gingival fibromatosis (HGF) is a rare gingival lesion ( 1 in $7,50,000)$ that presents as localized or generalized fibrotic enlargement of the attached gingivae as well as the gingival margin and interdental papillae. The gingiva is characterized as pink, firm and fibrous, with little tendency to bleed. It causes aesthetic disfigurement, speech disturbances, abnormal tooth movement and dental occlusion problems. HGF can present as an isolated feature or as a part of the syndrome. HGF inheritance is transmitted through both autosomal dominant and recessive modes. Case Series: This report presents hereditary gingival fibromatosis in a family, described with multiple affected subjects in four generations, consistent with an autosomal dominant mode of inheritance. Conclusion: It
\end{abstract}

Shivlal L Vishnoi

Affiliations: Senior Lecturer, Department of Periodontics, Manubhai patel Dental College and Hospital, Vadodara431001, Gujarat (INDIA).

Corresponding Author: Dr. Shivlal L Vishnoi, Manubhai patel Dental College and Hospital, Vishwajyoti Ashram, Near Vidhyakunj School, Munjmahuda, City - Vadodara7, Gujarat, India; Phone: 91-9586869196; Email: Vishnoi_shivlal@yahoo.com

Received: 26 December 2010

Accepted: 06 March 2011

Published: 30 June 2011 is a unique report of pedigree presenting gingival enlargement in four generation. Very few papers are published previously on this topic. Like other reported family, in current family variable expression of HGF was seen because most of the affected persons had generalized gingival enlargement while some had localized involvement.

Keywords: Hereditary gingival fibromatosis, Autosomal dominant, Aesthetic disfigurement

$$
* * * * * * * * *
$$

Vishnoi SL. Hereditary gingival fibromatosis: Report of four generation pedigree. International Journal of Case Reports and Images 2011;2(6):1-5.

$$
* * * * * * * * *
$$

doi:10.5348/ijcri-2011-06-36-CS-1

\section{INTRODUCTION}

Hereditary gingival fibromatosis (HGF) is a rare condition characterized by progressive enlargement of the gingivae, with a reported incidence of 1 in 750,000 [1].

Most cases of HGF appear to be inherited in an autosomal-dominant manner [2], although autosomal recessive inheritance has been reported [3]. The hyperplastic gingiva presents with normal color, has a firm consistency, and an abundance of stippling of the attached gingiva. Buccal/labial and lingual/palatal tissues may be involved in both the maxilla and the mandible. The degree of enlargement may vary from mild to severe and may be the same between individuals within the same family $[2,3]$. Most cases are seen from birth, but the condition may not be noticed until later childhood at the time of eruption of 
the deciduous or permanent teeth. This condition may appear as an isolated disorder, but in some cases it is associated with other conditions such as hypertricosis and epilepsy or with syndromes such as ZimmermanLaband, Murray-Puretic-Drescher, Cowden's and Cross syndrome [4].

In addition to cosmetic concerns, the compromised oral cavity may cause difficulty while eating, with speech, for hygiene, and oral competence. In addition, social consequences can be dramatic, forcing patients to lead isolated, reclusive lives.

\section{CASE REPORT}

\section{Family Details}

A 25-year-old male patient (of III ${ }^{\text {rd }}$ generation from our pedigree) reported with the chief complaint of excessive gum covering all of his teeth since last 15 years. On questioning he recalled that many of the members in his family are affected by same condition. The pedigree structure is shown below. In generation II, five out of eight offspring's were found to be affected. These five had a total of 22 children in generation III, out of whom nine were found to be affected, and from these nine only one person is married and he has two children, one of them is affected in generation IV.
Almost all individuals received an oral and dental examination, and based upon the presence or absence of gingival enlargement, were classified as affected or unaffected. To be classified as affected, an individual had to have keratinized gingival tissue covering at least one-third of the crowns of a minimum of five teeth. All individuals were asked about exposure to prescription and non-prescription of medications, and specifically for exposure to medications associated with gingival overgrowth, including phenytoin, cyclosporin, and calcium channel blockers [5]. No family members reported a history of hearing loss or epilepsy, and hypertrichosis was not observed in any individual. These clinical findings have been previously associated with syndromic forms of gingival fibromatosis.

Affected persons were identified by questioning of the other family members and this was subsequently confirmed by clinical examination of most of them, except for the reported patient's deceased grandfather and father in the generation I and in generation II, respectively.

Overall of 33 total members of the family, 16 were affected from all the generations at the given point of time.

Internal bevel gingivectomy done in the patient (of IIIrd generation from our pedigree) who reported to us with the complaint of excessive gum covering all of his teeth for esthetic purpose and same treatment was

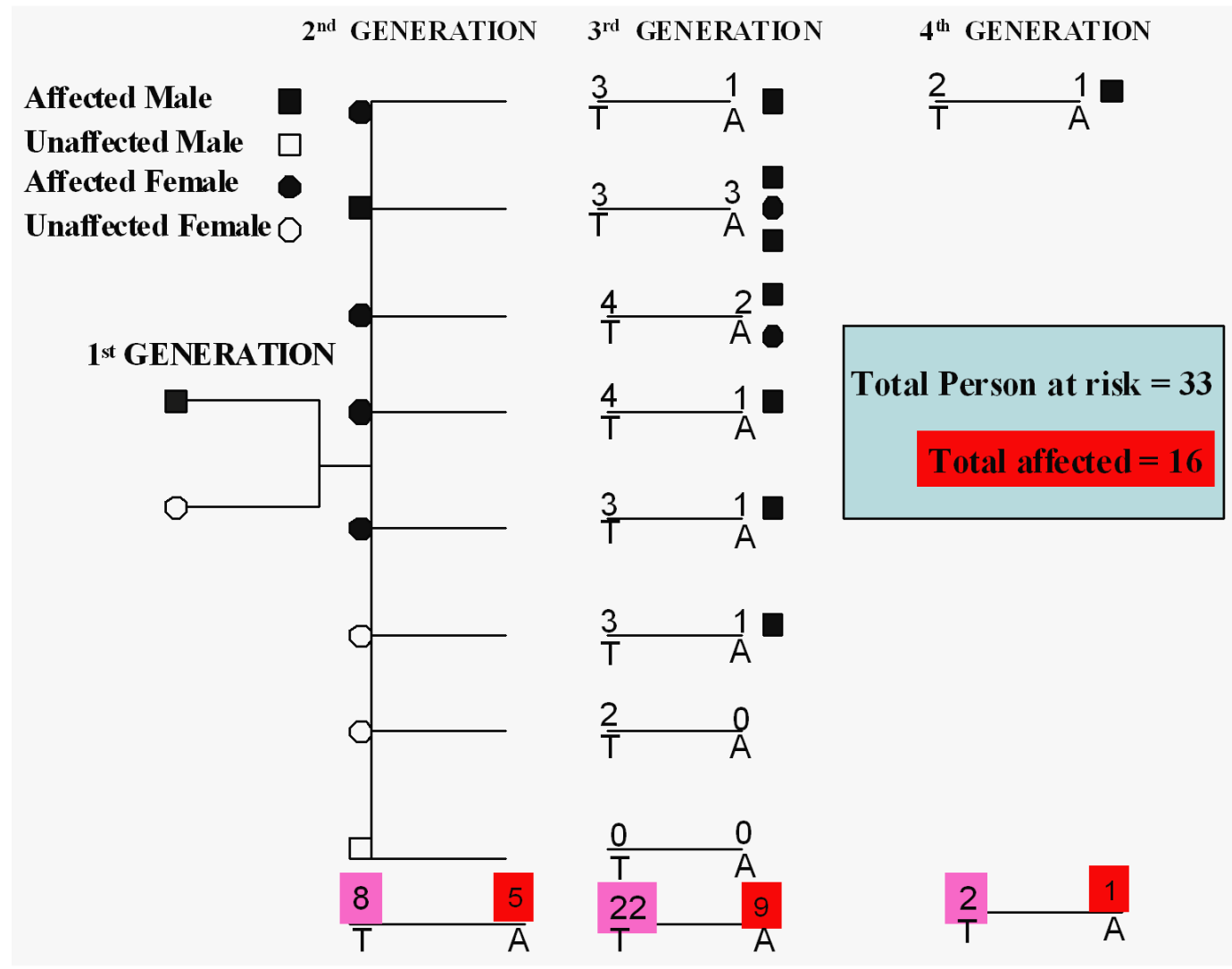

Figure 1: Pedigree of family with HGF: Affected persons are indicated by filled symbols. Male subjects represented by squares and female subjects by circles. T, total offspring; A, affected 


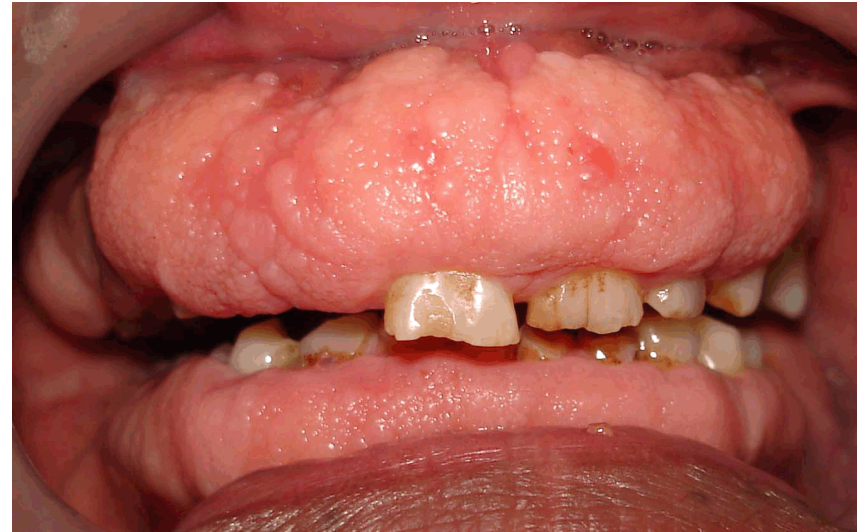

Figure 2: Hereditary Gingival Fibromatosis affecting maxillary and mandibular arches.

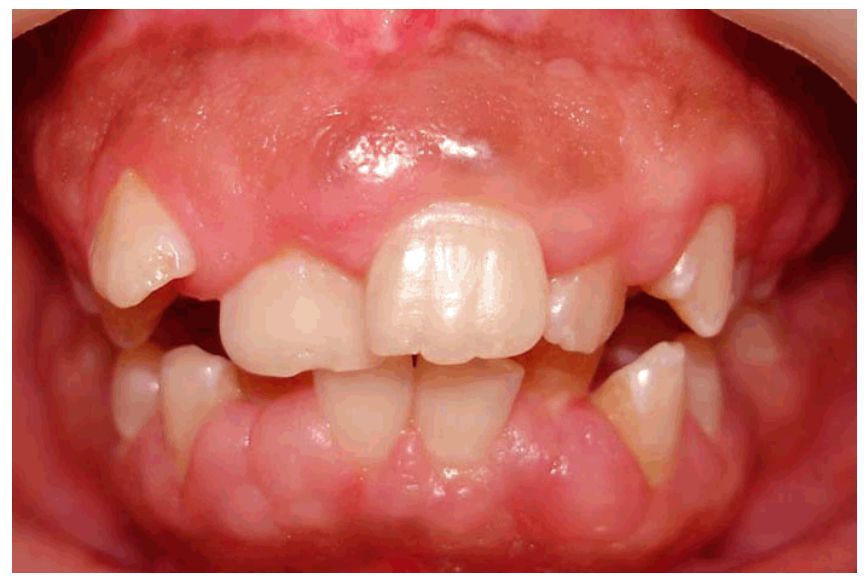

Figure 3: Pronounced Hereditary Gingival Fibromatosis shown in a child from pedigree.

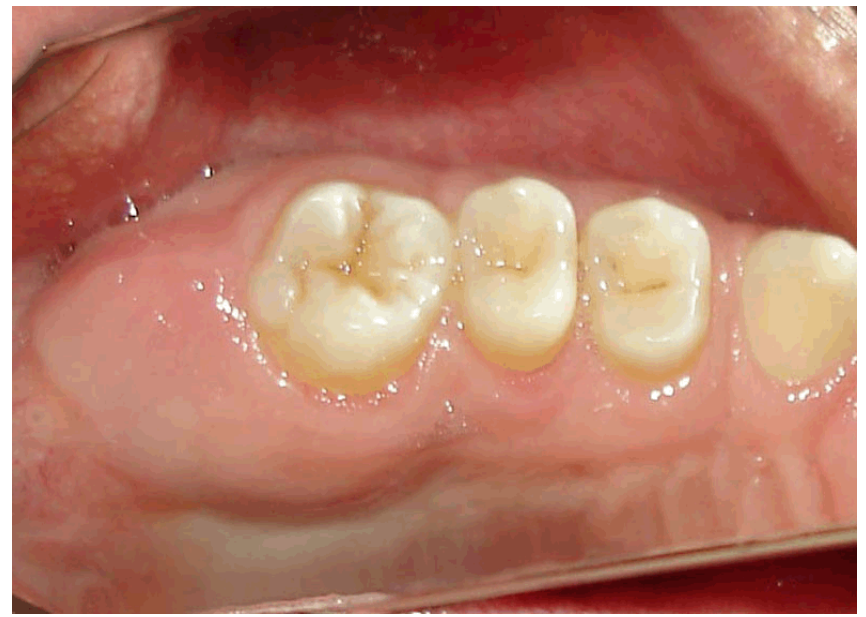

Figure 4: Prominent enlarged gingival tissue in maxillary tuberosity region.

prescribed to all the remaining patients from this pedigree, but while it is not a symptomatic condition, they refused for treatment.

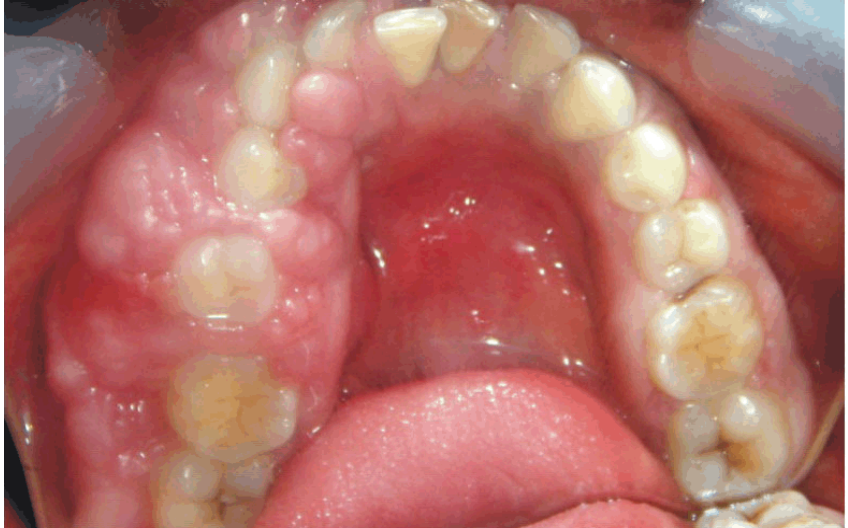

Figure 5: Abnormal tooth movement and dental occlusion problems associated with Hereditary Gingival Fibromatosis.

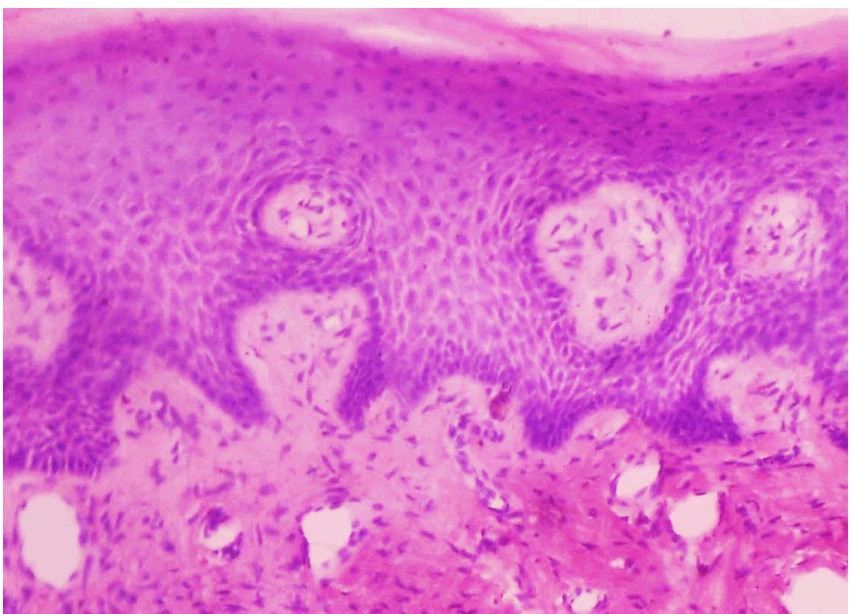

Figure 6: Histopathologic examination showing dense collagen fibers in underlying connective tissue.

\section{Clinical Features}

All affected family members had generalized gingival overgrowth involving all the gingiva around the upper and lower teeth of both deciduous and permanent dentitions (Figure 2-4). The quantity of hyperplastic gingival tissue varied among subjects, covering from a small part up to the whole crown of the tooth and may cause abnormal tooth movement and dental occlusion problems (Figure 5). In some cases, the growth was more exuberant in the tuberosity area causing deformity of the palate and impairing phonation and deglutition. Radiography showed no specific changes in the teeth or alveolar bone.

Biopsies were not done. However, in one case the gingival tissue was removed as excisional biopsy during periodontal surgical treatment as internal bevel gingivectomy procedure. Microscopically the connective tissue was formed by dense bundle of collagen fibers; the epithelium was hyperplastic with long rete pegs (Figure 6). 


\section{DISCUSSION}

Hereditary gingival fibromatosis (HGF) is a rare condition with reported prevalence of one in 7,50,000. Gingival fibromatosis may be seen as an isolated finding or in a family with multiple affected persons. When several members are affected, this suggests an autosomal dominant mode of inheritance [2]. Occasionally, HGF may present as an autosomal recessive disorder [3].

The gingival fibromatosis are clearly a heterogeneous group of disorders [2]. HGF in absence of any other abnormalities is more common than gingival fibromatosis associated with various syndromes. The combination of gingival enlargement, hypertrichosis, epilepsy and mental retardation is also commonly reported with syndromes that feature gingival fibromatosis [4]. Enlargement is not affected by plaque. Incidence and severity depend on the penetration of the mutated gene.

In this report of four generation members any of the associated abnormalities, seen in the rarer syndromes that feature gingival enlargement such as Zimmerman-Laband syndrome, Murray-Puretic Drescher syndrome, Rutherfurd syndrome, Ramon syndrome, Jones syndrome, Cross syndrome, Prunebelly syndrome, were not present.

Many of the previously reported cases of HGF have been sporadic [6,7], but it is not clear whether this is because the affected subjects inherited as autosomal recessive gene from each parents or they represented new mutation. Occasional families have been reported with few affected persons and history of consanguinity, consistent with an autosomal recessive disorder.

Families also have been reported that show a clearly autosomal dominant mode of inheritance. Although in India it is for the first time when we are going to report this extensive family pedigree of HGF. The largest groups thus far reported in the world were a four generation family with 50 affected offspring from a total of 132 members [2]. Also, a five generation family with 15 affected offspring [8] and another with 11 affected offspring from a total of 28 persons at risk in four generation [9] have been reported. These families showed evidence of variable expression.

Four generation family with 50 affected offspring from a total of 132 members reported by Bozzo et al (1994) [2], showed that penetrance of HGF appeared to be complete because there were no occasion when an unaffected person at risk was found to have had an affected child. Furthermore there was no evidence of variable expression because all affected persons had generalized gingival enlargement.

A four generation pedigree documented by Emerson TG (1965) [10] showed variable expression and is of particular interest in that sense the condition was transmitted by a subject at risk for the disorder who was apparently unaffected, indicating incomplete penetrance of HGF in that family.

In one report in the French literature, an apparently unaffected person transmitted the condition [11].

In the family in current report, findings were more similar to four generation pedigree documented by Emerson TG (1965) [10], but in contrast with family reported by Bozzo et al (1994) [2], there was a an unaffected subject at risk for the disorder from generation II transmitted condition indicating incomplete penetrance of $\mathrm{HGF}$ in the family. Like other reported family, in current family variable expression of HGF was seen because most of the affected persons had generalized gingival enlargement while some had localized involvement.

\section{CONCLUSION}

It is a unique report of pedigree presenting gingival enlargement in four generation. Very few papers are published previously on this topic. Like other reported family, in current family variable expression of HGF was seen because most of the affected persons had generalized gingival enlargement while some had localized involvement.

\section{$* * * * * * * * *$}

\section{Author Contributions}

Shivlal L. Vishnoi - Substantial contributions to conception and design, Acquisition of data, Analysis and interpretation of data, Drafting the article, Revising it critically for important intellectual content, Final approval of the version to be published

\section{Guarantor}

The corresponding author is the guarantor of submission.

\section{Conflict of Interest}

Authors declare no conflict of interest.

\section{Copyright}

(C) Shivlal L Vishnoi et al. 2010; This article is distributed under the terms of Creative Commons attribution 3.0 License which permits unrestricted use, distribution and reproduction in any means provided the original authors and original publisher are properly credited. (Please see www.ijcasereportsandimages.com /copyright-policy.php for more information.)

\section{REFERENCES}

1. Fletcher JP. Gingival abnormalities of genetic origin: preliminary communication with special reference to hereditary gingival fibromatosis. J Dent Res. 1966;45:597-612.

2. Bozzo L, de Almedia OP, Scully C, Aldred MJ. Hereditary gingival fibromatosis. Report of an 
extensive four-generation pedigree. Oral Surg Oral Med Oral Pathol. 1994;78(4):452-4.

3. Singer SL, Goldblatt J, Hallam LA \& Winters JC. Hereditary gingival fibromatosis with a recessive mode of inheritance. Case reports. Aust Dent J. 1993;38(6):427-32.

4. Gorlin RJ, Pinborg JJ \& Cohen Jr MM. Syndromes of the head and neck. $2^{\text {nd }}$ edition. New York: McGraw Hill; 1976. p. 329-336.

5. Hart TC, PaIIos D, Bozzo L, Almeida O P, Marazita ML, O'Connell JR and Cortelli JR. Evidence of Genetic Heterogeneity for Hereditary Gingival Fibromatosis J Dent Res. 2000;79(10):1758-64.

6. Takagi M, Yamamoto H, Mega H, Hsieh KJ, Shioda $\mathrm{S}$ and Enomoto S. Heterogenicity in the gingival fibromatosis. Cancer. 1991;68: 2202-12.

7. Witcop CJ. Heterogenicity in gingival fibromatosis. Birth defects. 1971;7:210-21.

8. Weski H. Elephantiasis gingivae hereditaria beobachtet anfunf Generation in einer familie. Dtsch Monattsschr Zahnheilkd. 1920;38:557-84.

9. Mirolli A. La elephantiasi familiare delle gingive. Arch Ital Chir, 1931; 29; 401-16.

10. Emerson TG. Hereditary gingival hyperplasia: a family pedigree of four generation. Oral Surg Oral Med Oral Path. 1965;19;1-9.

11. Cernea P, Garlopeau F, Marie M, Sand M. Les hyperplasies gingivales familiales. Rev Stomatol. 1955;56:620-6. 